\title{
The Impact of Using Google Search Engine and Yahoo Bing Network on Attracting New Customers Online and on the Effectiveness of Online Advertisements
}

\author{
Ala' A. Alkarablieh ${ }^{1}$ \\ ${ }^{1}$ Head of E-Markeing Department, Arabian Medical Relief (AMR), Jordan \\ Correspondence: Ala' Atef Jamil Alkarablieh, Head of E-Markeing Department, Arabian Medical Relief (AMR), \\ Jordan. E-mail: alaa_alkarableiah@hotmail.com
}

Received: April 10, 2016 Accepted: April 29, $2016 \quad$ Online Published: May 24, 2016

doi:10.5539/ijms.v8n3p163 URL: http://dx.doi.org/10.5539/ijms.v8n3p163

\begin{abstract}
This study aims at measuring the impact of using the most popular search engines: Google and Yahoo Bing networks on attracting new customers towards company websites and on the effectiveness of online advertisements. Quantitative research method and questionnaires were used by researcher to collect data.

The researcher distributed (129) questionnaires on (33) companies that use E-marketing in Jordan. Among those only (87) questionnaires were returned and (42) of which only were usable and valid for the statistical analysis. After executing the analysis, the study concluded that Google search engine has a direct effect on attracting new customers and on online advertisements effectiveness at $(\alpha \leq 0.05)$ level for companies using E-marketing in Jordan, while Yahoo Bing search engine has a direct effect on attracting new customers and on the effectiveness online advertisements at $(\alpha \leq 0.05)$ level for companies using E-marketing in Jordan.
\end{abstract}

\section{Introduction}

In this era of information technology and internet, many companies are competing to increase their profits and brand names by attracting new customers towards their websites online.

The majority of companies in Jordan are not well-aware of the importance of using search engines in E-Marketing (MOICT, 2011). Therefore, this study has come to explain the benefits that these companies will gain if they use this type of E-Marketing.

\subsection{Research Problem}

Since the majority of companies in Jordan are not well-aware of the importance of using search engines in E-Marketing (MOICT, 2011), this study intends to explain what are the benefits those companies will gain after using Google and Yahoo Bing search engines in attracting new customers towards their websites and in promoting their products and services online.

\section{Research Objectives}

This study aims at measuring the impact of using Google and Yahoo Bing search engines on attracting new customer's online and on the effectiveness of online advertisements for companies using E-Marketing in Jordan. In addition, to increasing companies' awareness of using search engines in E-Marketing for the purpose of increasing their profits and prevailing their brand names to customers.

\section{Literature Review}

\subsection{Search Engines Websites}

KarmaSnack.com statistics in 2013 indicated that the search engines Google, Yahoo and Bing are the major search engines in the world with a market share of more than $95 \%$ in comparison with other search engines. The figure below explains the most used search engines with the market share for each. 


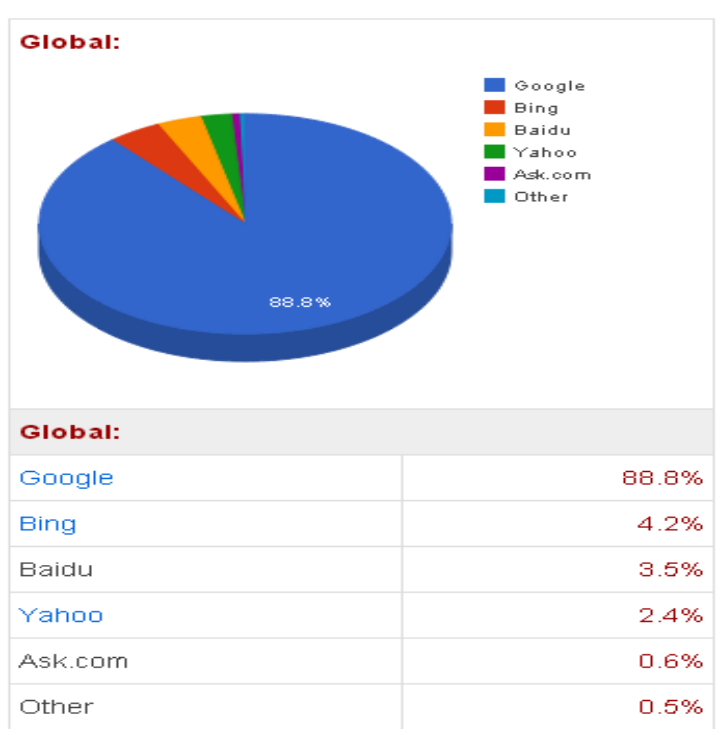

Figure 1. Serach engine market share

Source: KarmaSnack.com

Many factors, such as: effectiveness and efficiency are influenced by the use of search engines when surfing the internet. Those factors play a significant role in assessing and in distinguishing between the search engines, in terms of attracting new customers and on the effectiveness of online advertisements (Palanisamy, 2013). We can summarize the impacts of using search engines as follows:

1. The effect of search engines on brand names

- Increase audience's awareness of the brand name.

- Persuade companies to improve their brands logo design.

- Preserve users' loyalty to the brand.

- Increase the popularity of the brand.

2. Type of web browser: some search engines and web browsers are connected to each other. For example, the default page for Internet Explorer browser is Bing search engine, and the default page for Chrome browser is Google search engine. This has played an important role in attracting users to both sites.

3. Confidence in the search results: when results are more accurate and related to the search topic, the confidence in and the reputation of the search engine will increase, consequently it will attract more users and help in the success of online advertisements.

4. Ease of use and interaction with the graphical interface of the search engine.

5. Results speed plays a significance role in raising the popularity of the search engine.

6. Privacy: one of the most important features in any search engines. Many companies and organizations which have important information that could benefit other competitors have registered in search engines security services in order to protect and secure their privacy, therefore maintaining their current customers and attracting new ones.

\subsection{Google Search Engine}

Google is a global company based in the United States. It sells ads related to searches performed by users, and we can consider Google as the biggest and the most famous search engine worldwide, because it introduces to users products and services with high quality, high-speed display of results, and unique algorithms which gives it an advantage compared to the rest of search engines (Google, 2007).

According to Smith (2010); Google Company aims to be the first search engine in the world by becoming the main source of information collecting about all the products and services offered online. Google Company has produced many services to its users, which has distinguished it from the rest of search engines; the best known of which are: 
1. Search: indexing and delivering every web site.

2. Images: allow to search any picture on the Internet.

3. YouTube: allows users to upload and share any video.

4. Gmail: sending and receiving emails through the internet.

5. Map: providing directions for every trip in every city.

6. Books: providing access to every book published on the internet.

7. Blogger: publishing writings through blogs.

8. Chrome Browser: allows users to browse web pages with high speed and strong GUI.

Additionally, Google introduces many free tools that allow website administrators to improve website appearance on the search results page (SERP) by monitoring traffic and by identifying strengths and weaknesses (Weller \& Calcott, 2012; Ueland, 2012). For example:

1. Google Webmaster Tool: assists website administrators to have better control on how Google search engine interacts with their organizations' websites, and also helps to get useful information about the current status of websites. In addition, this tool introduces a variety of tasks, such as:

- Downloading XML Sitemap file.

- Analyzing and generating Robots.txt files.

- Removing links to unwanted sites that might be used by Google in the search results.

- Clarifying some issues related to Meta tag.

- Understanding the best research ways to gain access to organization websites.

- Identifying the preferred domain (URL).

- Getting a glimpse at how the pages are reached by Googlebot.

- Receiving notifications of violations of quality.

2. Google Analytic Tools: is one of the most important free tools provided by Google. It helps website administrators to monitor traffic on organizations website, through gathering information on following statistics, which provides the following (Plaza, 2010):

- Describes how users access organization websites and also the sources which contribute to this access, such as (search engines, direct visits or recommendations from other websites ... etc).

- Helps to control movement behaviors made by users on their websites, such as their actions towards goods and services provided on the organization website.

- Reveals website strengths which have contributed to attract customers to the website of the organization.

- Assists in measuring the impact of improvements made on website.

- Helps in making marketing campaigns more successful and effective.

- Google Trends: is a free tool that helps website administrators to learn more about popular keywords used in searching by Google users in a specific industry.

- Google Adwords Tools: is the main source of income for Google, which is a program provided by Google that allows website administrators to buy certain keywords to show their ads on search engine results pages when the user enters any of these keywords on the website. And being accounted for by CPC and CPM approach; this tool provides many options that allow administrators to have more controls on paid ads, such as determining geographical location, target language and so on (Weller \& Calcott, 2012).

\subsection{Yahoo! Bing Network}

Yahoo! Bing network is the new official name which reflects participation between both Microsoft Company and Yahoo! company, and which possesses $29 \%$ of the market share online; where advertisers can target a large number of the audience which amounts to 151 million users and especially the 45 million users who do not use Google search engine (Yahoo! Bing Network, 2013).

The Bing search engine has now become dominant on yahoo search engine, this means that when web admins create new campaigns on Bing the search results will appear directly on Yahoo search engine (Usmani et al., 2012) 


\subsubsection{Yahoo Search Engine}

Is a global company specialized in information technology that provides goods and personal services apart from searching, and introduces various tools for communication. The company provides its services for all continents of the world, primarily in the Americas, Europe, Middle East and Africa (EMEA). The company register estimated revenue of five million dollars during the financial year that ended in December 2012 and the number of employees were estimated by approximately 11,700 employees at the end of 2012 (Marketline, 2013).

According to Najjar (2008), the Yahoo Company offers a variety of services via various websites such as:

- Search (http://search.yahoo.com/): helps website administrators to conduct marketing research and monitor competitors online.

- Pictures (http://images.search.yahoo.com/): find photos.

- Video (http://video.search.yahoo.com/): helps in searching for, uploading, downloading and sharing videos online.

- Maps (http://maps.yahoo.com/): allow companies to determine their geographic locations across the Internet.

\subsubsection{Bing Search Engine}

Defined by MSN and Windows Live Search, and is called the decision engine. Bing has begun working since 2009 and is affiliated to Microsoft Corporation. It is considered a strong competitor for Google and Yahoo! Search engines.

Paid ads in Bing search engine are more efficient and attractive to customers compared to Google search engine, as it receives $42 \%$ of users versus $25 \%$ for Google search engine. In terms of the number of users who search by using search engines; However, Google search engine has more $89 \%$ of users compared to less than $9 \%$ for Yahoo! and Bing search engines put together. On the other hand, Bing search engine is superior over Google search engine in terms of the costs of advertising (CPC), as pay-Per-Click (PPC) on the search engine results page (SERP) in Bing reaches a minimum of $\$ 0.25$ compared to $\$ 0.75$ in Google (Twentyman, 2009).

Bing offers a variety of tools that help website administrators to improve their websites appearance, including (Najjar, 2008):

1. Bing Webmaster Tool: helps website administrators to monitor their advertising campaigns across Bing search engine through:

- Increasing the number of visits to the company website

- Clarifying the strengths and weaknesses of the website

- Discovering users' trends by research, which helps to know more about the market trends over the Internet

2. Bing Ads: allow to buy keyword ads and managing their advertising campaigns in Yahoo! Bing network.

\section{Previous Studies}

Martzoukou (2008) study aimed to examine graduate students' behavior when they are using search engines on the internet depending on their skills and experience, and also to measure the search engines' efficiency through the information retrieved and the levels of satisfaction expressed by their students. The study also compares between the numbers of the search engines - such as Google, Yahoo! and AltaVista in terms of the services provided by these sites and to what extent they are used by students. The study was conducted on 66 graduate students; a wide majority of whom were enrolled in relevant search engine courses or have experience in using search engines. The study uses quantitative research method that was carried through a questionnaire designed and distributed among students. The study deduced that $57.6 \%$ of students said that search engines were of good quality for use; $83.3 \%$ of students use Google search engine services and; $39.4 \%$ of the students are above average of satisfaction with the results provided by search engines.

A study conducted by Kaur et al. (2011) aimed to evaluate the most popular search engines' tools on the internet, such as those provided by Google, AltaVista, ASK.com, Bing and Yahoo on the basis of features and services offered by each search engine to its users. The researcher has used quantitative method using questionnaires to collect information. The study was conducted on 263 people who have the experience and concerns in using search engine tools, the study found that $75 \%$ of the respondents use search engines daily; $96 \%$ of the respondents use the Google search engine, and $92 \%$ of the respondents said that Google search engine is simple and easy to use, while $29 \%$ of respondents watch the first two pages on search engine results pages only. 
A study conducted by Jafarzadeh et al. (2011) aimed to create a new business model to explain search engine advertisements by measuring the factors that attract online marketers. The study used quantitative research method which depends on questionnaires, carried out on all the companies that use search engines to promote their products and services. The study found that using search engines in marketing contributes in promoting for goods and services and boost company sales.

A study conducted by Usmani et al. (2012) compared between the two most used search engines in the world; Google and Bing. The comparison was conducted on the basis of effectiveness, ability, and who can offer more favorable results that meet users' preferences. The study used a group of inquiries related to general topics, including the Computer Science domain. The study concluded that Google search engine provides more effective and accurate retrieval of information when the query is only one word, while the search engine gives better results when the query is made up of two or more words.

\section{Methodology}

The current study employs a quantitative approach consistent with the nature of the study problem and its questions. The population of the current study consists of 33 companies using E-marketing in Jordan.

The survey unit of analysis consisted of employees in IT and Marketing departments. To collect the primary data, (129) questionnaire were distributed to them, out of which (42) questionnaires were returned and only (87) questionnaire were suitable for statistical analysis.

The study focused on collecting the primary data about the companies on which the research was conducted through a structured questionnaire for the purposes of the study. The questionnaires were hand-delivered with a covering letter by the researcher to the managers, in order to complete the primary data required for the study. Hand-delivery of the questionnaire is beneficial, as the researcher may be asked to clarify or answer some questions, or otherwise listen to suggestions that may be raised by the respondents.

\subsection{Reliability Test (Cronbach's Alpha)}

Reliability test was used to test the consistency and suitability of the measuring tools. If Alpha Coefficients were above 0.80 , they were considered to be high, and if they were above 0.75 , they were accepted. The table below shows Cronbach's alpha for the variables which were above the accepted level.

Table 1. Cronbach's alpha for research variables

\begin{tabular}{lll}
\hline Variable & No. of Items & Cronbach's alpha \\
\hline Google & 9 & .689 \\
Yahoo! Bing network & 7 & .842 \\
Online advertisements & 4 & .790 \\
Attracting Customers online & 4 & .801 \\
\hline
\end{tabular}

\subsection{Validity}

To avoid any validity problems in our study we have taken measures to avoid confusion. We have chosen only respondents/companies who have previous experience in E-marketing and online business and all of the respondents were Marketing Mangers, IT Managers, a Website Designer, a Programmer, and System Analysts who actively use the internet and online services in their companies.

\section{Study Sample Characteristics}

As shown in the table below, the majority of the sample members were males $(81.6 \%)$. Most of the respondents had less than (5) years of experience. Over (67.8\%) of companies are small in size (less than 100 employee) and only $(33.5 \%)$ of them use E-marketing at high levels. About $(28.7 \%)$ of the respondents were specialized in E-marketing, while approximately (35.6\%) of companies earn an annual income of less than $100.000 \mathrm{JD}$. 
Table 2. Demographic profile of the respondents

\begin{tabular}{|c|c|c|}
\hline Demographics & Frequency & Percentage $\%$ \\
\hline Gender & - & - \\
\hline Male & 71 & 81.6 \\
\hline Female & 61 & 18.4 \\
\hline Total & 87 & $100 \%$ \\
\hline Years of Experience in the Company & - & - \\
\hline $1-5$ years & 41 & 47.2 \\
\hline $6-10$ years & 28 & 32.2 \\
\hline $11-15$ years & 15 & 17.2 \\
\hline More than 16 years & 3 & 3.4 \\
\hline Total & 87 & $100 \%$ \\
\hline Job Title & - & - \\
\hline E-Marketer & 25 & 28.7 \\
\hline General Manager & 14 & 16.2 \\
\hline Web Designer & 10 & 11.5 \\
\hline Programmer & 12 & 13.8 \\
\hline Software Engineering & 20 & 23.0 \\
\hline System Analysis & 3 & 3.4 \\
\hline Total & 87 & $100 \%$ \\
\hline Company Size (Employee No.) & - & - \\
\hline Small Size (less than 100) & 59 & 67.8 \\
\hline Medium size (101 and less than 500) & 15 & 17.3 \\
\hline Large Size (more than 501) & 13 & 14.9 \\
\hline Total & 87 & $100 \%$ \\
\hline Degree of Using E-marketing by Company & - & - \\
\hline Low & 22 & 25.3 \\
\hline Medium & 5 & 5.7 \\
\hline High & 31 & 35.6 \\
\hline Extremely high & 29 & 33.4 \\
\hline Total & 87 & $100 \%$ \\
\hline Company Annual Online Sales Volume & - & - \\
\hline Less than $100.000 \mathrm{JD}$ & 31 & 35.6 \\
\hline 100-500JD Thousand & 28 & 32.2 \\
\hline 501.000 - 1 Million JD & 8 & 9.2 \\
\hline More than 1 Million JD & 20 & 23.0 \\
\hline Total & 87 & $100 \%$ \\
\hline
\end{tabular}

\subsection{Descriptive Statics}

To obtain the general results of the study, the means and the standard deviations of different responses to the statements were calculated using Statistical Package for Social Sciences (SPSS). While the standard mean of all statements is above (3), the responses below are considered to be positive.

Table 3. Mean, standard deviation, level of importance of Google search engine

\begin{tabular}{|c|c|c|c|c|}
\hline No. & Sentence & Mean & St. $\mathbf{D}$ & Level of Importance \\
\hline 1 & Google search engine contributed in increasing traffic on the company website. & 4.22 & 0.807 & High \\
\hline 2 & $\begin{array}{l}\text { Google services such as: photos, maps and YouTube that have helped the company } \\
\text { to attract new customers. }\end{array}$ & 3.91 & 0.718 & High \\
\hline 3 & $\begin{array}{l}\text { Google services such as: photos, maps, and YouTube that have helped the company } \\
\text { to promote its products and services. }\end{array}$ & 3.85 & 0.681 & High \\
\hline 4 & $\begin{array}{l}\text { Google Webmaster Tools that have helped the company to possess more control } \\
\text { over advertising campaigns. }\end{array}$ & 3.84 & 0.986 & High \\
\hline 5 & The cost of advertising in Google search engine is low. & 3.74 & 0.620 & High \\
\hline 6 & Google search engine provides rapid response when used in e-marketing. & 3.71 & 0.828 & High \\
\hline 7 & $\begin{array}{l}\text { Using AdWords tools has contributed in promoting for the company products and } \\
\text { services over the Internet. }\end{array}$ & 3.64 & 1.033 & Mid \\
\hline 8 & $\begin{array}{l}\text { Using AdWords tools contributed to attract new customers to the company via the } \\
\text { Internet. }\end{array}$ & 3.36 & 1.326 & Mid \\
\hline 9 & Possessing high ranks in Google search engine results is easy and uncomplicated. & 3.34 & 1.150 & Mid \\
\hline
\end{tabular}


Table 4. Mean, standard deviation, level of importance of Yahoo Bing network

\begin{tabular}{lllll}
\hline No. & Sentence & Mean & St. D & Level of Importance \\
\hline 1 & $\begin{array}{l}\text { Yahoo! Bing Network contributed in increasing traffic on the company } \\
\text { website. }\end{array}$ & 3.23 & 1.092 & Mid \\
2 & $\begin{array}{l}\text { Bing webmaster tools helped the company to have more control over } \\
\text { advertising campaigns on Yahoo! Bing Network. }\end{array}$ & 3.20 & 1.187 & Mid \\
3 & $\begin{array}{l}\text { The cost of advertising in the Yahoo! Bing Network is low. } \\
4\end{array} \quad \begin{array}{l}\text { Yahoo! Bing Network is rapid in response when used in electronic } \\
\text { marketing. }\end{array}$ & 3.19 & 0.982 & Mid \\
5 & $\begin{array}{l}\text { Using Bing Ads tools has contributed to the promotion of company } \\
\text { products and services on the internet. }\end{array}$ & 3.16 & 0.958 & Mid \\
$\quad \begin{array}{l}\text { Using Bing Ads tools has contributed in attracting new customers to the } \\
\text { company via the Internet. }\end{array}$ & 3.10 & 0.995 & Mid \\
$\begin{array}{l}\text { Possessing high ranks in Yahoo! Bing Network results is easy and } \\
\text { uncomplicated. }\end{array}$ & 3.04 & 0.970 & Mid \\
\hline
\end{tabular}

Table 5. Mean, standard deviation, level of importance of online advertisements

\begin{tabular}{|c|c|c|c|c|}
\hline No. & Sentence & Mean & St. D & Level of Importance \\
\hline 1 & $\begin{array}{l}\text { It is easy for the company to control the online ads and edit their } \\
\text { content. }\end{array}$ & 4.10 & 0.822 & High \\
\hline 2 & $\begin{array}{l}\text { Online advertising facilitates communication between the company and } \\
\text { customers online. }\end{array}$ & 4.09 & 0.725 & High \\
\hline 3 & $\begin{array}{l}\text { Online advertising has contributed in increasing the value of the } \\
\text { company's goodwill. }\end{array}$ & 3.99 & 0.958 & High \\
\hline 4 & $\begin{array}{l}\text { The use of E-marketing tools; such as: Social Media, search engines, } \\
\text { e-mail and other tools has contributed in the promotion of the company } \\
\text { products and services. }\end{array}$ & 3.86 & 0.780 & High \\
\hline
\end{tabular}

Table 6. Mean, standard deviation, level of importance of attracting customers online

\begin{tabular}{lllll}
\hline No. & Sentence & Mean & St. D & Level of Importance \\
\hline 1 & $\begin{array}{l}\text { It is easy for the company to control the online ads and content editing. } \\
\text { Online advertising facilitates communication between the company and } \\
\text { customers online. }\end{array}$ & 4.09 & 0.816 & High \\
3 & $\begin{array}{l}\text { Online advertising has contributed in increasing the value of the } \\
\text { company's goodwill. } \\
\text { The use of E-marketing tools; such as: Social Media, search engines, } \\
\text { e-mail and other tools has contributed in the promotion of the company } \\
\text { products and services. }\end{array}$ & 3.61 & 0.881 & High \\
4
\end{tabular}

\subsection{Hypothesis Test}

To test the study's hypotheses, a simple regression analysis was used to analyze the relationship between Google search engine and Yahoo Bing network and their impact on attracting new customers and increasing the effectiveness of online advertisements. And in order to achieve the research objectives, this section will test the hypotheses as follows:

1. A simple regression analysis was conducted as shown in table 7 .

Table 7. The results of simple regression analysis of Google search engine's effect as a variable on attracting customers were as follows

\begin{tabular}{|c|c|c|c|c|c|c|c|c|c|}
\hline \multirow{2}{*}{ DV } & \multirow{2}{*}{$\mathbf{R}^{2}$} & \multirow{2}{*}{$\mathbf{F}$} & \multirow{2}{*}{ D.F } & \multirow{2}{*}{ Sig } & \multicolumn{5}{|c|}{ Regression Coefficient } \\
\hline & & & & & ID & B & SE & $\mathbf{t}$ & Sig \\
\hline Attracting & \multirow{3}{*}{0.154} & \multirow{3}{*}{15.164} & 1 & \multirow{3}{*}{0.000} & \multirow{3}{*}{ Google } & \multirow{3}{*}{0.714} & \multirow{3}{*}{.183} & \multirow{3}{*}{3.894} & \multirow{3}{*}{0.000} \\
\hline Customers & & & 83 & & & & & & \\
\hline Online & & & 84 & & & & & & \\
\hline
\end{tabular}


The results of the simple regression analysis show a regression in Google search engine variables against attracting customer as shown in table (7). It shows that Google search engine variable reveals $15 \%$ percent of the variance, as demonstrated by the results $(\mathrm{R} 2=0.154, \mathrm{~F}=15.164$, Sig. $=0.000)$. Therefore, the null hypothesis is rejected and the alternative hypothesis is accepted; rendering that Google search engine affects in attracting customers towards companies which use E-marketing in Jordan at $(\alpha \leq 0.05)$.

2. Simple regression analysis was conducted to test the second hypothesis as shown in table 8 .

Table 8. The results of simple regression analysis of Yahoo Bing network variable against attracting customers were as follows

\begin{tabular}{|c|c|c|c|c|c|c|c|c|c|}
\hline \multirow{2}{*}{ DV } & \multirow{2}{*}{$\mathbf{R}^{2}$} & \multirow{2}{*}{$\mathbf{F}$} & \multirow{2}{*}{ D.F } & \multirow{2}{*}{ Sig } & \multicolumn{5}{|c|}{ Regression Coefficient } \\
\hline & & & & & ID & B & SE & $\mathbf{t}$ & Sig \\
\hline \multirow{3}{*}{$\begin{array}{l}\text { Attracting } \\
\text { Customers Online }\end{array}$} & \multirow{3}{*}{0.322} & \multirow{3}{*}{40.322} & 1 & \multirow{3}{*}{0.000} & Yahoo! & \multirow{3}{*}{0.470} & \multirow{3}{*}{.074} & \multirow{3}{*}{6.350} & \multirow{3}{*}{0.000} \\
\hline & & & 85 & & Bing & & & & \\
\hline & & & 86 & & network & & & & \\
\hline
\end{tabular}

The results of the simple regression analysis show a regression in Yahoo Bing network variables against attracting customer as shown in table (8). It shows that Yahoo Bing network variable explained 32\% of the variance, as demonstrated by the results $(\mathrm{R} 2=0.322, \mathrm{~F}=40.322$, Sig. $=0.000)$. Therefore, the null hypothesis is rejected and the alternative hypothesis is accepted, which states that Google search engine affects in attracting customers towards companies which use E-marketing in Jordan at $(\alpha \leq 0.05)$.

3. Simple regression analysis was conducted to test the third hypothesis as shown in table 9.

Table 9. The results of simple regression analysis of Google search engine variable against online advertisements were as follows

\begin{tabular}{|c|c|c|c|c|c|c|c|c|c|}
\hline \multirow{2}{*}{ DV } & \multirow{2}{*}{$\mathbf{R}^{2}$} & \multirow{2}{*}{$\mathbf{F}$} & \multirow{2}{*}{ D.F } & \multirow{2}{*}{ Sig } & \multicolumn{5}{|c|}{ Regression Coefficient } \\
\hline & & & & & ID & B & SE & $\mathbf{t}$ & Sig \\
\hline \multirow{3}{*}{ Online Advertisements } & \multirow{3}{*}{0.247} & \multirow{3}{*}{27.167} & 1 & \multirow{3}{*}{0.000} & \multirow{3}{*}{ Google } & \multirow{3}{*}{0.727} & \multirow{3}{*}{.140} & \multirow{3}{*}{5.212} & \multirow{3}{*}{0.000} \\
\hline & & & 83 & & & & & & \\
\hline & & & 84 & & & & & & \\
\hline
\end{tabular}

The results of the simple regression analysis show a regression in Google search engine variables against online advertisements as shown in table (9). It shows that the Google search engine variable explained $24 \%$ percent of the variance, according to the results of ( $\mathrm{R} 2=0.247, \mathrm{~F}=27.167$, Sig. $=0.000$ ). Therefore, the null hypothesis is rejected and the alternative hypothesis is accepted, which reveals that Google search engine affects online advertisements in companies which use E-marketing in Jordan at $(\alpha \leq 0.05)$.

4. Simple regression analysis was conducted to test the fourth hypothesis as shown in table 10.

Table 10. The results of simple regression Analysis of Yahoo Bing network variable against online advertisements were as follows

\begin{tabular}{|c|c|c|c|c|c|c|c|c|c|}
\hline \multirow{2}{*}{ DV } & \multirow{2}{*}{$\mathbf{R}^{2}$} & \multirow{2}{*}{$\mathbf{F}$} & \multirow{2}{*}{ D.F } & \multirow{2}{*}{ Sig } & \multicolumn{5}{|c|}{ Regression Coefficient } \\
\hline & & & & & ID & B & SE & $\mathbf{t}$ & Sig \\
\hline \multirow{3}{*}{ Online Advertisements } & \multirow{3}{*}{0.079} & \multirow{3}{*}{7.301} & 1 & \multirow{3}{*}{0.008} & Yahoo! & \multirow{3}{*}{0.191} & \multirow{3}{*}{071} & \multirow{3}{*}{2.702} & \multirow{3}{*}{0.008} \\
\hline & & & 85 & & Bing & & & & \\
\hline & & & 86 & & network & & & & \\
\hline
\end{tabular}

The results of the simple regression analysis show a regression in Yahoo Bing network variables against online advertisements as shown in table (10). It shows that the Yahoo Bing network variable revealed about $8 \%$ percent of the variance, according to the results of $(\mathrm{R} 2=0.079, \mathrm{~F}=7.301$, Sig. $=0.000)$. Therefore, the null hypothesis is rejected and the alternative hypothesis is accepted, which states that the Google search engine affects online advertisements in companies which use E-marketing in Jordan at $(\alpha \leq 0.05)$. 


\section{Conclusion and Recommendations}

The purpose of this study is to measure the impact of using large search engines on attracting customers online and on increasing online advertisement effectiveness in companies that use E-marketing and E-commerce in Jordan.

In e-marketing, it was found that many tools can be used by companies; such as: Social media marketing, E-mail marketing, affiliate marketing, search engine marketing and so on.

Using search engines in E-marketing has grown rapidly, and many global companies now are more focused on and concerned with this type of E-marketing, which has become vital for businesses to succeed in E-marketing.

Google and Yahoo Bing network are the largest search engines in the world, and they provide many techniques for companies to promote their products and services such as: "Search engines results page (SERP)" and "Network advertisements".

In spite of the fact that more and more companies are using these techniques internationally, very little research has attempted to analyze how companies can make use of these techniques in Jordan. Therefore, this research will help in shedding light on the usage of search engines in E-marketing and e-commerce companies in Jordan.

The results show a statistical significant effect of using Google search engine and Yahoo Bing network on attracting new customers online at the significance level $(\alpha \leq 0.05)$ in companies that use E-marketing and e-commerce in Jordan.

This means that using search engines contributes in attracting more visitors and in increasing traffic on company websites. Another result presented in this research shows that there is a statistically significant effect of using search engines on online advertisements at the significance level $(\alpha \leq 0.05)$ in companies that use E-marketing and e-commerce in Jordan. This means that they contribute in increasing the promotion of company products and services via the internet, and thus will lead to increase profits and revenues of investment ROI. This hypothesis is consistent with the study (Johansson, 2012). Furthermore, descriptive results show that the use of pay-per-click advertising has contributed in raising the level of the company's goodwill as well as its ability to target a particular geographical area, as well as contributing in increasing the number of the keywords of company websites. This hypothesis is consistent with the study of (Alkarablieh, 2015).

After completing the study, the researcher has concluded the following recommendations:

1) Companies must show interest in E-marketing and hire experts in marketing on search engine

2) Using Google search engines in E-marketing brings more benefits compared with Yahoo Bing network in Jordan.

3) Search engine marketing is easy to use in comparison with other E-marketing tools.

4) Google search engine contributed in increasing traffic on the company website.

5) Google services such as: photos, maps and YouTube that have helped the company to attract new customers.

6) Google services such as: photos, maps, and YouTube that have helped the company to promote its products and services.

7) Google Webmaster Tools that have helped the company to possess more control over advertising campaigns.

8) The cost of advertising in Google search engine is low.

9) Online advertising facilitates communication between the company and customers online.

10) Online advertising has contributed in increasing the value of the company's goodwill.

11) Companies should provide courses to their employees in the E-marketing departments at their premises on benefiting from marketing using search engines.

\section{References}

Alkarablieh, A., \& Khraim, H. (2015). The Effect of Using Pay Per Click Advertisement on Online Advertisement Effectiveness and Attracting Customers in E-marketing Companies in Jordan. International Journal of Marketing Study, 7(1), 180-189.

Calcott, L., \& Weller, B. (2012). A guide to using Google ad words. ABA Bank Marketing, 44(6), 18-21.

Chau, M., Wong, C., Zhou, Y., Qin, J., \& Chen, H. (2010). Evaluating the use of search engine development tools in it education. Journal of the American Society for Information Science and Technology, 61(2), 288-299. 
Google. (2007). Marketing and advertising using Google ${ }^{\mathrm{TM}}$ targeting your advertising to the right audience. Ottawa: library and archives Canada.

Jafarzadeh, H., Aurum, A., \& D’Ambra, J. (2011). Factors Affecting the Success of Businesses in Effective Utilization of search Engine Advertising.

Johansson, M. (2012). Paid Traffic Pay per click advertising in Swedish companies (Master Thesis). University of Gothenburg, Gutenberg, Sweden.

Karma Snack Forecasts. (2013). Search engine market share. Retrieved from http://www.karmasnack.com/about/search-engine-market-share/

Kaur, M., Bhatia, N., \& Singh, S. (2011). Web search engines evaluation based on features and end-user experience. International Journal of Enterprise Computing, 1(2), 1-19.

MaeketLine. (2013). Yahoo! Inc SWOT Analysis. Retrieved from www.Marketline.com

Martzoukou, K. (2008). Students' attitudes towards web search engines increasing appreciation of sophisticated search strategies. Libri, (58), 182-201. http://dx.doi.org/10.1515/libr.2008.019

Ministry of IT. (2011). Published at AlRai Daily News paper, Amman Jordan. Retrieved from http://www.alrai.com/article/4354.html

Najjar, O., Salem, M., \& Samara, S. (2008). Google vs Yahoo. http://dx.doi.org/10.2139/ssrn.1375406

Palanisamy, R. (2013). Evaluation of search engines aconcptual madel and research issues. International Journal of Business and Management, 8(6), 1-15. http://dx.doi.org/10.5539/ijbm.v8n6p1

Plaza, B. (2010). Google Analytics. Online (Business Source Premier), 34(5), 33-37.

Smith, R. (2010). Google means every. Research Technology Management, 53(1), 67-69.

Twentyman, J. (2009). Technology Bing or Google? Director, 63(1), 21-21.

Ueland, S. (2012). 12 SEO free Google tools. Retrieved from http://www.practicalecommerce.com/articles/3597-12-Free-Google-SEO-Tools

Usmani, T., Pant, D., \& Bhatt, A. (2012). A comparative study of google and bing search engines in context of precision and relative recall parameter. International Journal on Computer Science and Engineering, 4(1), 21-34.

\section{Copyrights}

Copyright for this article is retained by the author(s), with first publication rights granted to the journal.

This is an open-access article distributed under the terms and conditions of the Creative Commons Attribution license (http://creativecommons.org/licenses/by/3.0/). 